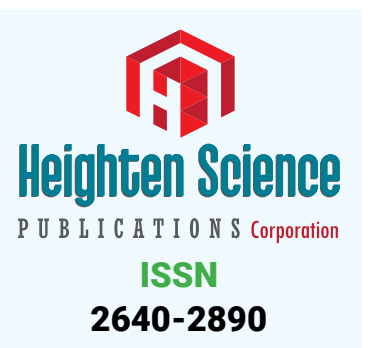

*Address for Correspondence: Akowuah Jones Asafo, Department of Agricultural Economics, Agribusiness and Extension, Kwame Nkrumah University of Science and Technology, Kumasi, Ghana, Email: asafojones60@gmail.com

Submitted: 20 June 2019

Approved: 01 July 2019

Published: 02 July 2019

Copyright: (C) 2019 Akowuah JA and Danquah BA. This is an open access article distributed under the Creative Commons Attribution License, which permits unrestricted use, distribution, and reproduction in any medium, provided the original work is properly cited

Keywords: ANC service; Postnatal care; Utilization; Satisfaction; Logit model; Urban Ghana

Check for updates

\title{
Determinants of women's perceived satisfaction on Antenatal care in urban Ghana: A cross-sectional study
}

\author{
Akowuah Jones Asafo ${ }^{1 *}$ and Danquah Benedicta Adoma² \\ 'Department of Agricultural Economics, Agribusiness and Extension, Kwame Nkrumah \\ University of Science and Technology, Kumasi, Ghana \\ ${ }^{2}$ Department of Accounting, School of Business, Kwame Nkrumah University of Science and \\ Technology, Kumasi, Ghana
}

\section{Abstract}

Despite evidence on major interventions on the uptake and scale up of interventions meant to promote maternal health care services, little is known about adequate use of such program in urban Ghana among reproductive aged women. This study examined the determinants of women's Satisfaction on antenatal care use in selected health facilities in the Kwabre East Municipality of Ghana. Using facility-based cross-sectional survey design, a three-stage sampling technique was conducted to sample 220 women attending postnatal care at selected public health facilities. Open-ended questionnaires were used to obtain data from respondents. Descriptive statistics and inferential statistics including binary logit regression model were used to analyze the data with the help of SPSS and STATA software. Logit analytical framework was computed to determine equations of variance. The association between antenatal care use and women's satisfaction was determined and assessed using Pearson's $\chi^{2}(2)$ test indicating $1 \%$ was run. Most women (92.7\%) had at least four ANC visits during their entire pregnancy. The results indicate standard deviation of 7 with $81 \%$ regular ANC visits and $19 \%$ irregular. Most women (55\%) received care by one caregiver, followed by women (35\%) who received care by two caregivers and women $(10 \%)$ who were cared for by three caregivers. The regression results showed varying utilization levels of $10 \%, 5 \% \& 1 \%$ ANC satisfaction. System induced factors aimed at promoting maternal care use satisfaction are suggested.

\section{Introduction}

It is acknowledged globally that the low use of prenatal and maternal health services has directly contributed to the high rate of adverse birth outcomes [1]. Antenatal care (ANC) continues to be one of the safest maternal care interventions aimed at significantly reducing maternal and perinatal morbidities [2]. Among other reasons, ANC uitlization ensures effective management of prenatal morbidities, facility delivery, postpartum care and to manage complications in order to improve the health outcomes of mother and fetus [3-5]. Nonetheless, the entire healthcare system arrangement with effective referrals, package and quality of antenatal are paramount for the satisfaction of antenatal care [6]. Hence, there is little evidence on the satisfaction, content and quality of antenatal care offered to pregnant mothers in developing countries [7]. Studies have suggested that low rate of ANC attendance and institutional delivery in most developing countries are borne by the dissatisfaction pregnant women experience from caregivers [8]. Thus, the quality of ANC services sustainably provided to pregnant women is vital [9].

Pregnant women are provided with the opportunity to have interactive engagements with nurses, midwives, doctors and other caregivers among the broader healthcare 
system during ANC visits. Again, ANCs offer pregnant women the chance to take and make appropriate lifestyle decisions and choices respectively. ANC interventions, when carefully followed positively impact on the survival and health of mother and fetus to help detect and manage complications $[6,8]$.

The rate of ANC use in Ghana according to the Multiple Indicator Cluster Survey conducted in Ghana by the Ghana Statistical Service is 87\% [10], compared with the documented average of $79 \%$ for all lower-middle income countries [11]. Related studies by $[12,13]$ reveal $85 \%$ of pregnant women in Ghana receive at least one antenatal visit by skilled health professional before delivery. The overall ANC utilization rate in Ghana is high compared to other developing countries [10]. However, there are geographic variations of ANC use in Ghana as pregnant women in urban areas (73\%) make four or more ANC visits compared to their counterparts in rural areas (55\%). This baseline rate on ANC use did not come out of the moon, but by the conscientious efforts undertaken by the government of Ghana to promote maternal health care. In an attempt to tackle the menace of high rate of maternal mortality, morbidity and to ensure improved access, quality and continuous ANC use among pregnant women, the government of Ghana introduced focused antenatal care (FANC) in 2002 as recommended by the World Health Organization (WHO) [14]. Unlike the traditional ANC where care is provided by different caregivers, the FANC is client-centred, individualised, and comprehensive with emphasis on detecting complications rather than risk assessment [14]. Through ANC utilization, education on health promotion and preventive health services are sought for $[6,11]$.

Some studies including $[9,14-23]$ have reported on direct correlation between antenatal care visits and clients' satisfaction. As reported by [24] in Ghana, the free maternal healthcare policy was first introduced in September 2003 as a pilot project in the central, upper east, upper west, and the northern regions. It was later scaled up to the six remaining regions in April 2005 [24]. All services except laboratory tests for pregnant mothers are free. Among other benefits of the policy is the free National Health Insurance Scheme (NHIS) registration, which offers low-risk pregnancy care undertaken by caregivers and high-risk pregnancy care by consultants and other skilled health personnel $[13,21]$. The works of $[9,21]$ are revealing as they bring to the fore the realities on the ground on the satisfaction of ANC use among pregnant women in the developing world. However, key components to ANC use including waiting time and trimester variations among respondents are conspicuously missing. The studies of $[14-16,18,23]$ assume the interpretivism tradition of qualitative enquiry of which generalization becomes impossible. Again, a systematic review conducted by [19] deals with the attitudes and behaviors of maternal health care providers in interactions with clients using quotes and quotations. Hence, could not be enough in determining the predictors to antenatal care among pregnant women in urban Ghana.

Data from the Kwabre East Municipal Health Directorate [25], reveal irregular pattern of both antenatal and postnatal visits. The total annual attendance for antenatal use in 2011 was astronomically recorded as 666,089 with 1,825 as daily average visits, compared to postnatal visits of 88,918 with daily average of 244 . In 2012 , total annual attendance for antenatal visit greatly fell to 22,863 with daily average of 63 while 2,517 turnouts were recorded as Postnatal with 7 visits as the daily average. Total Antenatal cases again increased in 2013 to 25,212 with daily average of 69 while postnatal visits further increased to 3,530 with a daily average of 10 visits. However, the Antenatal visits in 2014 fell again to 22,625 with daily average of 62 while postnatal cases recorded further increased to 3,879 with daily average of 11 visits. On the predictors of pregnant women's satisfaction on ANC use, key indicators including stage of pregnancy, waiting time, acquisition of knowledge on ANC use, attitude of health staff, number of caregivers that attend to clients, physical accessibility, and the ANC services rendered to patients have not been altogether considered in the available literature. With efforts 
in promoting maternal health care on increasing ANC use among pregnant women in periurban Ghana, this study investigates the level of satisfaction on ANC use and its influence on the optimum use of the free maternal healthcare policy.

The current study was conducted in the Kwabre East Municipal Assembly, a periurban locale in the Ashanti Region of Ghana.

\section{Research hypothesis}

The current study is theoretically informed by the following hypotheses.

$H_{0}$. Perceived satisfaction has no significant influence on pregnant women's use of ANC in urban Ghana.

$H_{1}$. Perceived satisfaction has a significant influence on pregnant women's use of ANC in urban Ghana.

\section{Data and Methods}

\section{Study design and sampling}

The study forms part of a larger research that assessed the socio-economic determinants of antenatal care utilization of pregnant mothers in selected health facilities in the Kwabre East Municipality of Ghana. The study adopted a facilitybased cross-sectional survey design to investigate the predictors of satisfaction on ANC use among pregnant women in the municipality, using four selected facilities, specifically, Asonomaso, Mamponteng, Antoa and Sakra Wonoo. These health facilities are publicly owned and purposively sampled based on the administrative divisions of the municipality and the free maternal healthcare policy introduced by the Ghana Government in 2003.

The current study, therefore, assumes a three-stage sampling technique in the selection of respondents. At the first stage, purposive sampling technique was used to select four health facilities in the Kwabre East Municipality. The study population was selected based on the level of antenatal care attendance at each health facility. Using the Municipal Health Information Management System software (MHIMS), a list constituting 1010 pregnant women was selected from the combined registers of ANC units of the sampled health facilities. The proportional stratified sampling technique was used to select 220 pregnant women for the study using simple random sampling in each health facility. Structured questionnaires were used to collect data from study participants.

The sample size was obtained by using the fractional approach, which suggests that any fraction of an intended population that is $10 \%$ or more is deemed representative especially if the sample is scientifically designated [26]. In a related study by [27], it was revealed that a sample size of $5 \%$ of a population of study is considered to achieve its purpose if it is scientifically chosen. Hence, the sample size of $22.6 \%$ of the total population from the selected health facilities is estimate to be scientifically chosen. Hence, the proportionate stratified sampling was used to select the sample sizes using the formula; $n=(n i / N) S$, where $n i=$ facility population, $N=$ total population and $\mathrm{S}=$ sample size. The same formula was applied based on the variance in population of study respondents from selected facilities.

As a result, the margin of error for the determination of the sample size was 0.02 and the proportion of the study population likely to agree that the satisfaction of ANC use is a major public health concern is assumed at 10\% (0.10). The figures were then substituted into the formula outlined by [28] for determining the sample size for the study. The formula is given as:

$$
\frac{\mathrm{n}=\mathrm{P}^{1}\left(1-\mathrm{P}^{1}\right)}{[\mathrm{Sep}]^{2}}
$$


where $\mathrm{P}^{1}=$ estimate of proportion of the population with a particular characteristic.

$\mathrm{SEp}=$ acceptable margin of error

$\mathrm{n}=$ sample

$\frac{\mathrm{n}=0.10(1-0.10)}{[0.02]^{2}}$ Therefore, the sample size for the study was 225 .

\section{Data collection and analysis}

Data for the study were gathered using a face-to-face interview where structured questionnaires were employed to obtain data about the predictors of pregnant women's satisfaction on ANC use. Data were sought from respondents on key indicators of antenatal care including sociodemographic characteristics, stage of pregnancy, waiting time, acquisition of knowledge on ANC use, attitude of health staff, number of caregivers that attend to clients, physical accessibility, and the ANC services rendered to patients. Using the municipal health information management system software [25], a list of pregnant women with varying trimesters aged between 16-49 was obtained from the antenatal care units of the sampled health facilities from $15^{\text {th }}$ November to $1^{\text {st }}$ December, 2015. Consequently, the simple random sampling technique using the lottery method was adopted to select 220 pregnant women for the study. Data collected from respondents included demographic characteristics, health status, family planning services, social support systems, quality of service, choice of facility, level of utilization, and views on caregivers.

Raw data for the study were first entered into SPSS version 21, and then imported to STATA version 20 statistical package for final analysis. Descriptive statistics in the form of standard deviation, means, and percentages were carried out using tables. Again, the binary logistic regression analysis was computed to evaluate the difference in the level ANC satisfaction in relation to the relevant variables. Again, to assess the strength of association and statistical significance in bivariate analysis, the logit model was adopted to determine odds ratio, Chi-square, and $95 \% \mathrm{CI}$ for odds ratio were calculated to determine their significance.

\section{Ethical consideration}

Ethical clearance with reference CHRPE/AP/407/15 was sought from the Department of Community Health of the Kwame Nkrumah University of Science and Technology and the Komfo Anokye Teaching Hospital. In addition, formal consent was obtained from individual study participants in the selected health facilities who agreed to be part of the study..

\section{Analytical framework}

With variations in levels of satisfaction of ANC use and the stage of trimester in pregnancy, pregnant women in the third trimester may either be seen as having fully utilized and satisfied with antenatal care services or not depending on number of visits and the level of care resulting in a binary dependent variable $y_{i}$. The binary dependent variable $y_{i}$ takes on the values of zero (if not satisfied with ANC services received) and one (if satisfied with the ANC services received).

Table 1: Study facilities and their Selected Sample Sizes.

\begin{tabular}{|c|c|c|c|}
\hline Facility & Ni & N/n & ni $=\mathbf{N i}-\mathbf{n}(\mathbf{N})$ \\
\hline Asonomaso & 337 & $1010 \mid 220$ & $\mathbf{7 3}$ \\
\hline Mamponteng & 400 & $1010 \mid 220$ & 87 \\
\hline Antoa & 135 & $1010 \mid 220$ & 30 \\
\hline Sakra Wonoo & 138 & $1010 \mid 220$ & 30 \\
\hline Total & $\mathbf{1 0 1 0}$ & $\mathbf{2 2 0}$ & $\mathbf{2 2 0}$ \\
\hline Source: Authors' Construct. & & & \\
\hline
\end{tabular}


The probability of observing a value of one is:

$$
P_{r}=\left(y_{i}=\frac{1}{x_{i} \beta_{i}}\right)=1-F\left(x_{i} \beta_{i}\right)
$$

where $F($.$) is a cumulative distribution function, it is a continuous, strictly$ increasing function that takes a real value and returns a value which ranges from 0 to 1. Consequently, the probability of observing the zeros is:

$$
P_{r}\left(y_{i}=\frac{0}{x_{i} \beta_{i}}\right)=F\left(-x_{i} \beta_{i}\right)
$$

Given above specification, the maximum likelihood estimation approach can be used to estimate the model.

The dependent variable $y_{i}$ is an unobserved latent variable that is linearly related to by the equation:

$$
y_{i}=\beta_{i} x_{i}+\mu_{i}
$$

Where $\mu_{i}$ a random disturbance term and $x_{i}$ is independent variable which the influence number of antenatal visits. The observed dependent variable is determined by whether $y_{i}$ exceeds three or otherwise:

$$
y_{i}=\left\{\begin{array}{l}
\text { if } y_{i}^{*}>0 \\
0 \text { if } y_{i}^{*} \leq 0
\end{array}\right.
$$

where

$y_{i}^{*}$ is the threshold value for $y_{i}$. This study adopts the logit model to analyze the data, and the empirical model is specified as:

$$
\begin{aligned}
& y_{i}=\propto_{0}+\propto_{1} X_{1}+\propto_{2} X_{2}+\propto_{3} X_{3}+\propto_{4} X_{4}+\propto_{5} X_{5}+\propto_{6} X_{6}+\propto_{7} X_{7}+\propto_{8} X_{8}+ \\
& \propto_{9} X_{9}+\propto_{10} X_{10}+\propto_{11} X_{11}+\propto_{12} X_{12}+\varepsilon
\end{aligned}
$$

where variables, their description, and their expected sign are shown in table 2.

\section{Results}

\section{Characteristics of study sample}

Table 2 show the background characteristics of respondents used for the current

Table 2: Descriptive characteristics of respondents on satisfaction of ANC use.

\begin{tabular}{|c|c|c|}
\hline Variables & Description & Expected sign \\
\hline$X_{1}$ & Age of respondents & + \\
\hline$X_{2}$ & Household size of respondents & + \\
\hline$X_{3}$ & Occupational status of respondents & + \\
\hline$X_{3}$ & Primary education & + \\
\hline$X_{5}$ & Secondary/SHS education & - \\
\hline$X_{6}$ & Vocational/technical education \\
\hline$X_{7}$ & Tertiary education & + \\
\hline$X_{8}$ & By car (as a means of utilising ANC) &,+- \\
\hline$X_{9}$ & By walking &,+- \\
\hline$X_{10}$ & Others (any others means of utilizing ANC) \\
\hline$X_{11}$ & SakraWonoo health centre & - \\
\hline$X_{12}$ & Antoa health centre & + \\
\hline$X_{13}$ & Choice of facility for ANC services & - \\
\hline$X_{14}$ & Accessibility of ANC services & - \\
\hline$X_{15}$ & Satisfaction of ANC services; 1 = satisfied, $0=$ not satisfied &,+- \\
\hline$X_{16}$ & Attitude of caregivers; 1 = satisfied, $0=$ not satisfied &,+ \\
\hline$X_{17}$ & Number of caregivers that attend to patients; $1=$ satisfied, >2=not satisfied &,+- \\
\hline
\end{tabular}


study. It presents the independent variables used by the study and their corresponding outcomes of expected signs in relation to the logit model used. Table 3 also presents the study variables, frequencies and percentages associated with each category as age group, mean household size, level of education, employment status, health insurance status, and health facility ANC was attended. Generally, the study respondents were found to be young. The average age of respondents was 29 years with a standard deviation of 7 years. More than half of study respondents $56 \%(n=124)$ of the 220 study population were within the 21-29 age group, $24 \%$ (56) were in the 30-39 age bracket, with the age brackets of $16-20$ and $40-49$ both had $10 \%$ of the study population. Though most women had formal education, yet, the level of education attained among respondents was reported low. Among the study population, 14\% $(n=31)$ had tertiary education, $15 \%(n=32)$ had vocational/technical education, $27 \%$ $(\mathrm{n}=60)$ had secondary/SHS education, 30\% $(\mathrm{n}=65)$ had middle/JHS education, $9 \%$ $(n=20)$ had primary education with $5 \%(n=12)$ of the women had no formal education. This observation is consistent with the survey by the Ghana Statistical service [10], that female education in Ghana is generally low. Majority (85) of the pregnant women used for the study were employed. Also, most pregnant women (39) attended ANC at the Mamponteng health centre, followed by the facility at Asonomaso (32), followed by the Sakra Wonoo facility (15) and Antoa health (14), being the least. Among the study participants, $16(7 \%)$ were traditionalists, 64 (29\%) of respondents were Moslems and the majority of $140(64 \%)$ women being Christians. The study reveals that the level of health insurance subscription was encouraging. Over half (74) of the women used as study respondents had health insurance coverage under the national health insurance scheme (NHIS).

\section{Level of ANC utilization}

The result on the general level of ANC use is presented in table 4. Utilization is defined as the frequency of times a pregnant mother attends a health facility during her pregnancy stage [29-31]. For clarity, the study outlines utilization as either regular ( 4 or more visits) or irregular ( 0 to 3 visits). The results show that majority

\begin{tabular}{|c|c|c|}
\hline Variables & Frequency & Percentage \\
\hline \multicolumn{3}{|l|}{ Age distribution } \\
\hline $16-20$ & 22 & 10 \\
\hline $21-29$ & 124 & 56 \\
\hline $30-39$ & 52 & 24 \\
\hline $40-49$ & 22 & 10 \\
\hline Mean & 29 & - \\
\hline SD & 7 & - \\
\hline Mean household size & 3.25 & - \\
\hline Employed & 186 & 85 \\
\hline Unemployed & 34 & 15 \\
\hline Had no formal education & 12 & 5 \\
\hline Had primary education & 20 & 9 \\
\hline Had middle/JHS education & 65 & 30 \\
\hline Had secondary/SHS education & 60 & 17 \\
\hline Had vocational/technical education & 32 & 15 \\
\hline Had tertiary education & 31 & 14 \\
\hline Had NHIS card & 163 & 74 \\
\hline \multicolumn{3}{|l|}{ Religion } \\
\hline Christians & 140 & 64 \\
\hline Moslems & 64 & 29 \\
\hline Traditionalists & 16 & 7 \\
\hline Did not have NHIS card & 57 & 26 \\
\hline Mamponteng facility users & 85 & 39 \\
\hline Asonomaso facility users & 71 & 32 \\
\hline SakroraWonoo facility users & 34 & 15 \\
\hline Antoa facility users & 30 & 14 \\
\hline
\end{tabular}




\begin{tabular}{|c|c|c|c|}
\hline Variables & Category & Frequency & Percentage \\
\hline \multicolumn{4}{|c|}{ Stage of accessing ANC } \\
\hline & $1^{\text {st }}$ Trimester & 89 & 40 \\
\hline & $2^{\text {nd }}$ Trimester & 83 & 38 \\
\hline & $3^{\text {rd }}$ Trimester & 49 & 22 \\
\hline \multicolumn{4}{|c|}{ Physical accessibility } \\
\hline & Walk & 115 & 52 \\
\hline & Car & 92 & 42 \\
\hline & Other means & 13 & 6 \\
\hline \multicolumn{4}{|c|}{ Duration of ANC care } \\
\hline & $1-20$ minutes & 95 & 43 \\
\hline & 20-40 minutes & 105 & 48 \\
\hline & $40-60$ minutes & 20 & 9 \\
\hline \multicolumn{4}{|c|}{ Knowledge on ANC use } \\
\hline & Through friends & 22 & 10 \\
\hline & Through relatives & 36 & 16 \\
\hline & During health visit & 112 & 51 \\
\hline & Through the media & 50 & 23 \\
\hline \multicolumn{4}{|c|}{ Number of caregivers on clients } \\
\hline & 3 Caregivers & 22 & 10 \\
\hline & 2 Caregivers & 76 & 35 \\
\hline & 1 Caregiver & 122 & 55 \\
\hline \multicolumn{4}{|c|}{ Attitude of caregivers } \\
\hline & Poor & 11 & 5 \\
\hline & Satisfactory & 51 & 23 \\
\hline & Good & 158 & 72 \\
\hline \multicolumn{4}{|c|}{ Level of ANC use } \\
\hline & Regular & 178 & 81 \\
\hline & Irregular & 42 & 19 \\
\hline
\end{tabular}

of respondents (81\%) responded regular to ANC use. However, only $42(19 \%)$ of pregnant women responded to ANC use as irregular (Table 4). To fully establish the pattern of ANC among pregnant women in the study area, the stage of pregnancy among respondents was reported in table 4 . The study results reveal that majority (40\%) of pregnant women first accessed ANC in their first trimester, followed by $38 \%$ of respondents receiving ANC in their second trimester, with $22 \%$ attending ANC in the third trimester of their pregnancies. The stage of pregnancy among pregnant women used as study respondents is further illustrated in figure 1. Further regression analysis was run with all study predictors to determine their significance level in table 7.

\section{Physical accessibility of ANC by pregnant women}

The result on accessing ANC among pregnant women is presented in table 4 . Accessibility was defined by the study parameters according to the standards of the World Health Organization that "accessibility implies the continuing and organized supply of care that is geographically, financially, culturally and functionally within easy reach of the whole community". The results indicate that respondents' physical accessibility by foot. More than half of the respondents (52\%) accessed ANC in health facilities by means of walking; $42 \%$ accessed ANC by means of car with $6 \%$ of respondents accessing ANC through other means. Additionally, to establish the pattern of ANC among pregnant women, duration of ANC use was explored. The results reveal that 105 out of the 220 respondents spent 20-40 minutes anytime they accessed antenatal care. Some 95 pregnant women also accessed ANC for a duration of 1-20 minutes with only 20 people spending 40-60 minutes anytime they accessed ANC.

\section{Satisfaction of ANC use}

The study further explored the dynamics of satisfaction on ANC use among pregnant women. The general perception on satisfaction to antenatal care use was high. Majority (92.7\%) rated satisfaction to ANC services as good compared to the 


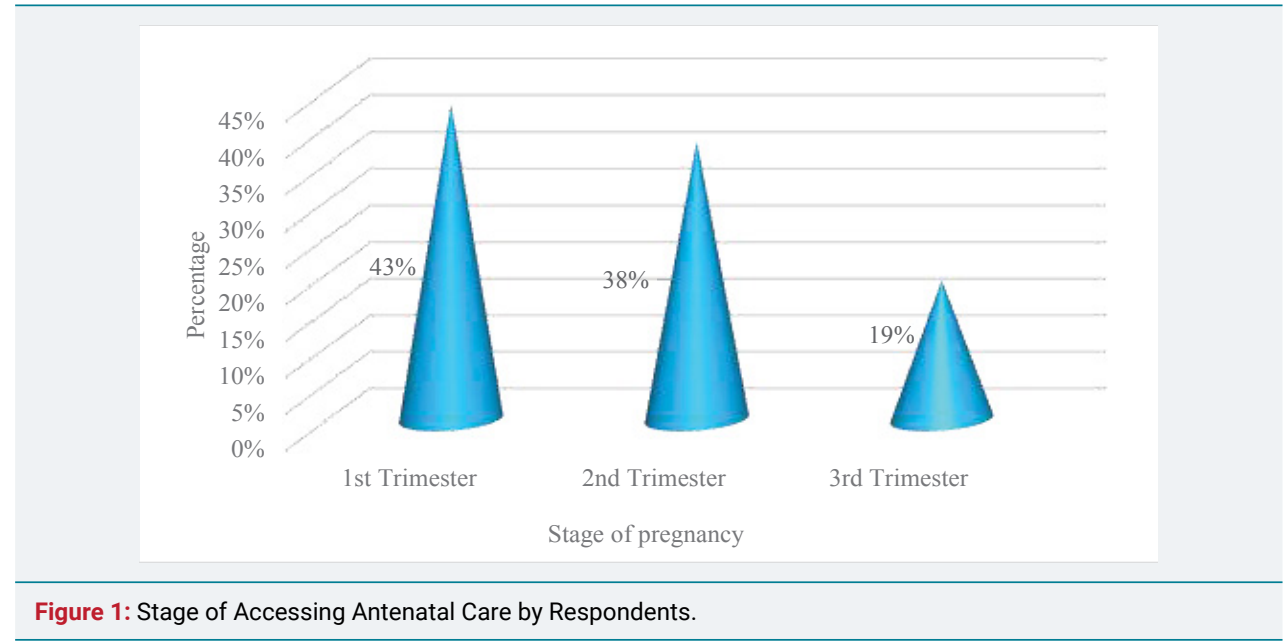

minority (7.3\%), who responded 'no' (poor) to ANC satisfaction in table 5. The study outcome reveals a high level of satisfaction among pregnant women used in the study and who received the recommended four ANC visits. The results in table 5 indicate a majority of $204(92.7 \%)$ were satisfied with the antenatal care they receive in their visits to facilities. However, only 16 (7.3) responded they were not satisfied with the ANC services they receive. Since satisfaction to ANC use was adopted by the study parameter as a dependent variable, further analysis was run using the logit model to determine its correlation level to ANC use. Hence, the Pearson chi-square statistic of 23.21, displayed in table 6 is highly significant at 1\% indicating that there is a strong association between pregnant womens' satisfaction with the ANC services rendered at health facilities and their regular visits to these facilities. Further regression analysis was run with all study predictors to determine their significance level in table 7.

Again, the number of healthcare workers that rendered services to respondents was considered by the study. Thus, the number of caregivers that always responded to pregnant women during ANC visits was considered by the study in reference to the recommendations of the World Health Organization. It was revealed in table 4 that out of the 220 sampled respondents, majority 122 (55\%) of respondents indicated, that 1 nurse took care of them during ANC visits. This was followed by 76 (35\%) people who responded that two nurses took care of them during ANC sessions and 22 (10) respondents indicated that three nurses take care of them for ANC. The study observation on the number of caregivers that responded to study respondents is further displayed in Figure 2.

\section{Attitude of health staff and knowledge on ANC use}

Table 4 presents the results on respondents' perception on the attitude of health staff during ANC visits. Thus, pregnant women were asked to rate the attitude of caregivers on ANC use in health facilities visited. In general, the perception of the attitude of health staff was high. These perceptions in the study circumstances include poor, satisfactory and good. Majority of the women (72\%) rated the attitude of care as good. This was followed by the rating of the attitude of health staff by respondents as satisfactory (23\%), with $5 \%$ of the women rating the attitude of caregivers as poor (Table 4). The study parameters considered the importance on the knowledge of the need for ANC use and where the knowledge was obtained and its usefulness among pregnant women. The results, therefore, indicate majority (51\%) of respondents had knowledge on the need and importance to use ANC services during their visit to the health facility. This was followed by the use of the media (23\%) on the need and importance to utilize ANC. Again, $16 \%$ and $10 \%$ of the respondents reported that they always get educated on the need to utilize ANC through their relatives and friends respectively (Table 4). 
Table 5: Women's perceived satisfaction on ANC use.

\begin{tabular}{|c|c|c|c|}
\hline Variables & Category & Frequency & Percentage \\
\hline ANC Satisfaction (At least 4 visits) & & & \\
\hline & Yes (Good) & 204 & 92.7 \\
\cline { 2 - 3 } & No (Poor) & 16 & 7.3 \\
\cline { 2 - 3 } & Total & 220 & 100 \\
\hline
\end{tabular}

Table 6: Pearson chi-square on ANC satisfaction.

\begin{tabular}{|c|c|c|c|}
\hline & Value & df & Asymp. Sig. (2-sided) \\
\hline Pearson Chi-Square & 23.211 & 1 & 0.00 \\
\hline
\end{tabular}

Table 7: Regression of ANC factors for the selected health facilities.

\begin{tabular}{|c|c|c|c|c|c|c|}
\hline \multicolumn{7}{|c|}{ Dependent variable: Satisfaction of ANC use (dummy) } \\
\hline Independent Variables & Coef $(\beta)$ & Std. Err. & z & Marg. Eff. (dy/dx) & Std. Err. & z \\
\hline \multicolumn{7}{|l|}{ Socio-economic characteristics } \\
\hline Age & 1.42 & 0.38 & $3.57 * \star \star$ & 0.04 & 0.01 & $8.46^{\star \star \star}$ \\
\hline HHSize & 2.83 & 1.01 & $2.83^{\star \star \star}$ & 0.08 & 0.02 & $3.72^{\star \star \star}$ \\
\hline Occupational Status dummy & 5.15 & 2.61 & $1.97 * \star$ & 0.11 & 0.03 & $3.42^{\star \star *}$ \\
\hline \multicolumn{7}{|l|}{ Educational Status } \\
\hline Primary & -4.29 & 2.56 & $-1.87^{\star}$ & -0.10 & 0.05 & $-1.93^{\star *}$ \\
\hline Secondary/SHS & -3.61 & 1.63 & $-2.85^{\star \star}$ & -0.09 & 0.03 & $-2.87 * \star \star$ \\
\hline Vocational/Technical & -2.75 & 1.83 & -1.49 & -0.06 & 0.04 & -1.47 \\
\hline Tertiary & -1.60 & 2.04 & -0.78 & -0.03 & 0.04 & -0.78 \\
\hline \multicolumn{7}{|l|}{ Geographical distance } \\
\hline By Car & -2.57 & 1.48 & $-1.70^{\star}$ & -0.07 & 0.03 & $-2.07 \star \star$ \\
\hline Others & -1.69 & 4.75 & -0.35 & -0.04 & 0.12 & -0.47 \\
\hline \multicolumn{7}{|c|}{ Facility } \\
\hline Asonomaso & -4.76 & 1.87 & $-2.37 \star \star$ & -0.11 & 0.03 & $-3.57 * \star \star$ \\
\hline Sakra Wonoo & -5.84 & 2.61 & $-2.23^{\star \star}$ & -0.16 & 0.05 & $-2.78^{\star \star \star}$ \\
\hline Antoa & -0.65 & 2.07 & -0.32 & -0.01 & 0.04 & -0.39 \\
\hline \multicolumn{7}{|l|}{ Level of ANC satisfaction } \\
\hline Stage of pregnancy & -2.37 & 1.55 & -1.24 & -0.01 & 0.03 & $-2.24 \star \star$ \\
\hline Waiting time & 2.25 & 1.03 & 1.89 & 0.03 & 0.03 & $1.37^{* *}$ \\
\hline Physical accessibility dummy & -1.51 & 1.44 & -1.17 & -0.04 & 0.04 & -1.27 \\
\hline Knowledge on ANC use & -1.51 & 2.68 & $-3.19 * \star \star$ & -0.25 & 0.04 & $-3.51^{\star}$ \\
\hline Attitude of staff dummy & 2.56 & 1.78 & 1.44 & 0.06 & 0.03 & $1.89 * \star$ \\
\hline Number of caregivers on client & 3.30 & 1.53 & $2.25^{\star \star}$ & 0.10 & 0.04 & $3.57^{\star \star \star}$ \\
\hline ANC services rendered & 3.53 & 2.37 & 1.72 & 0.11 & 0.03 & $2.25^{\star \star}$ \\
\hline Constant & -39.61 & 10.11 & -3.25 & & & \\
\hline \multicolumn{7}{|l|}{ 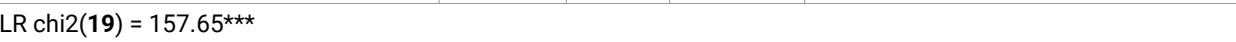 } \\
\hline Pseudo R2 $=0.83$ & & & & & & \\
\hline \multicolumn{7}{|l|}{ Log likelihood = -18.69 } \\
\hline 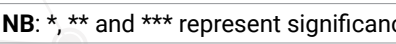 & $\%, 5 \%$ & resp & ely. & & & \\
\hline
\end{tabular}

NB: * ** and *** represent significance at $10 \%, 5 \% \& 1 \%$ respectively.

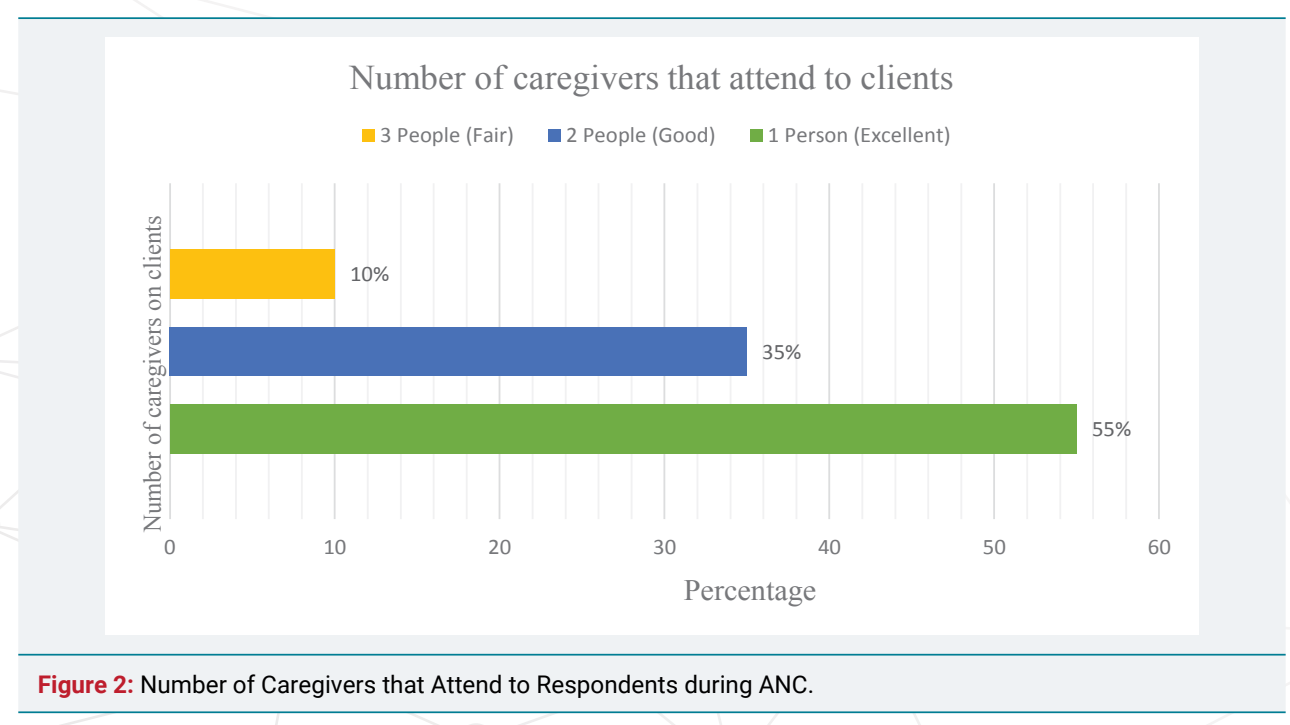




\section{Discussion of Results}

The current study focused on the determinants of perceived satisfaction of ANC use and its influence on actual use of ANC services among pregnant women in urban Ghana after the introduction of the free maternal healthcare services in Ghana. The entire package intervention is meant to bridge the gap between the rich and poor as it seeks to reduce financial constraints among pregnant women [24]. Among the package of the free maternal care introduced in Ghana was to make ANC services easily sought for with much satisfaction to pregnant women. Thus, the intervention was introduced to woefully reduce maternal mortality and morbidities. The current study was informed by this baseline scenario, to determine if the intended target of the government of Ghana in tandem with the recommendations by the World Health Organization has been a reality or still not a mirage. Therefore, the free maternal healthcare policy in Ghana should be encouraged.

The study acknowledges that physical access to ANC is in general satisfactory and easily fetched among urban folks. It is revealed that most respondents did not have to travel far distances to access ANC services in health facilities. Thus, most pregnant women either lived close to health facilities or have to travel few distances to access antenatal care. The much ease with which pregnant women experience high level of physical access to ANC use in urban Ghana is very promising in the study outcome. It is therefore recognized in the available literature that the distance covered to access health care services with ease can influence the rate of health care utilization among health seekers [29,32-34]. Hence, increased access to health care is a major concern to maternal health promotion, since it has the propensity to reduce mortality, infant morbidity and prevent birth complications.

The stage of pregnancy in accessing ANC use among urban women was also satisfactory. The study results reveal a significant number of women were able to receive the recommended ANC visits outlined by the WHO. Thus, the study shows a high rate of antenatal care use among respondents especially with women in their first trimester which increases satisfaction of ANC services. This observation of high rate of ANC attendance among study participants is so encouraging. Hence, early and routine ANC use help to reduce negative pregnancy outcomes including pregnancy anaemia, intermittent preventive treatment for malaria during pregnancy (IPTp), management of infections including HIV, and the identification and management of obstetric complications including tetanus [35]. Again, early and routine antenatal care use offer the opportunity for intense knowledge on the adoption of exclusive breastfeeding and proper childcare to women of childbearing age. Women have the opportunity to engage service providers for better clarification on ANC services received. There is intense satisfaction for antenatal care use when provider-client interaction is provided [21]. Thus, the high rate of early ANC use among study respondents may be as the result of the FANC introduced by the government of Ghana in 2002. This study observation is consistent with a report by the Ghana Health Service [35], which indicates that more than $80 \%$ of all pregnant women had at least one ANC visit to a skilled provider in 2016 survey report. Again, early and routine ANC use help pregnant women to fully utilize the four WHO recommended visits. This observation, therefore, confirms the results of previous studies conducted by the [36,37]. This study report contradicts the study of [38]. which indicates that less than $50 \%$ of 19,211 women in 13 West African Countries used as study participants, did not use ANC services in their first trimester.

The study results found out that women's satisfaction to ANC use is highly dependent on the duration of time spent in health facilities. The study variables defined duration as the 'contact time' ANC services are sought for in a facility [39], however, defines it as 'realized accessibility' as the actual utilization of health care. Duration of antenatal care was considered as the real contact time pregnant women spent in seeking health care. 
In determining the institutionalized pattern of ANC in urban Ghana, respondents were asked of the average time spent on accessing services at the selected facilities. The study reveals a significant number of women were able to access ANC services within a space of one hour in the facilities they visited. This observation is good since it builds in women the trust and confidence in the general healthcare system. Considering the myriad of activities women get themselves into, spending less times during antenatal sessions will eventually bring about satisfaction of the services used. The current study is therefore in agreement with [30], that ideally accessing ANC should be within forty (40) minutes. However, the observation is in contrast to the study by [40], on factors influencing adolescents' utilization of Antenatal care services in Bulawayo, Zimbabwe that pregnant adolescents were not satisfied with services rendered because of long delays in accessing ANC. Hence, long waiting time at facilities reduces the utilization of desired services rendered to patients [41]. The study is therefore in consistent with the findings of [42] in Tari and [43], which concluded that the average waiting time for accessing antenatal care service by pregnant women was less than one hour.

The study also found that all women who participated in the study were taken care of by a number of skilled care workers including Nurses, Midwives and Doctors. Hence, the study included the number of health care attendants that attended to patients to determine its significance level among expectant mothers utilizing ANC in urban Ghana. This is good since fewer ANC attendants helps to ensure maximum security on health care history of patients. Hence, few health care attendants ensures intense satisfaction to patients when antenatal care becomes a critical opportunity for health providers to deliver intensive care, support and information to pregnant women. All pregnant women used in the study were attended to the recommended number of health stated according to the regulations of the World Health Organization. This significant association of number of caregivers on patients' ANC use may be attributed to the focused antenatal care intervention introduced by the government of Ghana in 2002. Hence, policies on social support systems should always have crosscutting and forward-looking attributes to benefit all social groups. Globally, it is observed among pregnant women who use ANC services, that the fewer the number of health care attendants, the greater the quality and satisfaction of care rendered [6]. This observation is consistent with studies by [44,45], on the utilization of antenatal care services in Atwima Nwabiagya District which revealed that majority of studied respondents were attended to by not more than three health attendants.

The study has also revealed that the degree of ANC satisfaction by urban women is mostly influenced by the knowledge of antenatal care use. Pregnant women who rated high satisfaction to ANC use were 12 times significantly more likely to access the recommended four or more visits than their counterparts who rated satisfaction as poor. Although the desired and early visits to ANC use are vital to detect pregnancy complications and for safe delivery for mother and child, the knowledge on ANC use to pregnant mothers determines the sufficient utilization and satisfaction of the service [46]. Hence, the knowledge of pregnant mothers on ANC in urban Ghana was explored. In view of this, pregnant mothers were asked how they heard of the need to access antenatal care. The medium of knowledge about ANC the study considered were through friends, relatives, during a visit to health facility and the media. This observation is consistent with studies by [12]. [47-49] and [4], that pregnant mothers resort to different means to update their knowledge on antenatal care. Also, it is in agreement to survey by the Ghana Statistical Service $[10,50]$, that pregnant mother rely on varied sources for information on antenatal care. To further determine the association between the knowledge of ANC use and satisfaction, the level of ANC use was explored. The result of the study suggest that urban women continue to utilize ANC services due to the renewed interest and satisfaction that comes with utilization. Hence, women who regularly use attend ANC visits are 4 times more than their fellows 
whose ANC attendance is irregular. This observation may strongly be due to the focused antenatal care intervention and the sources of knowledge on antenatal care use. The study results indicate that for ANC services to be scaled up and adequately used by pregnant women, the broader healthcare system should endeavour to deliver quality services. This finding is consistent with the survey from [10], which indicated that antenatal care coverage is slightly higher in urban areas (98\%) than in rural areas (95\%).

The current study revealed that the level of ANC satisfaction during facility visits is closely related to the attitude of caregivers that always render care to pregnant women. The study searched to find out how the attitude of care givers influenced antenatal care services received by expectant mothers. Pregnant women who perceived the attitude of caregivers on ANC use to be good or satisfactory were significantly more likely to have the recommended four or more ANC visits than their counterparts who perceived attitude to be poor. Hence, the attitude of health care providers is acknowledged to have a significant influence on the behaviour of pregnant women in accessing antenatal care services in Africa [15,24,44,51]. The utilization of ANC services becomes worsened when expectant mothers perceive the attitude of care givers as rude and hostile with discouraging words used on patients [52]. There is therefore the need to promote broader health system, which encompasses all Organizations both public and private, resources, and people whose ultimate goal is to improve health of people especially maternal health.

\section{Study limitations}

The current study acknowledges some limitations of methodological approach used which might have caused for some biases in the entire study method. The study with its parameters, was confined to the satisfaction of pregnant women on the use of antenatal care services in a particular urban centre in Ghana. Again, the purposive and proportionate stratified sampling techniques with the use of the ANC register at facilities may have easily led to selection of respondents. Hence, the selection of few health facilities contributed to the exclusion of some facilities of the entire District. Also, some study variables such as satisfaction, attitude of health staff and knowledge on the importance of ANC were difficult to measure in the regression analysis. Hence, descriptive statistical tools like tables, frequencies, figures, and bar charts represented dummy variables. Notwithstanding, due to the homogeneous nature of respondents, the exclusion of potential respondents from other facilities did not affect the trustworthiness of the study results. One other major limitation of the current study was the sample 220 urban women. This figure was purely a part of the entire potential pregnant women who may have been used as study respondents. Therefore, the study result could not be wholly generalized for all women in urban Ghana.

\section{Conclusion and Recommendation}

The current study has shown greater satisfaction of antenatal care use among pregnant women in the Kwabre East Municipality of Ghana. Most pregnant women in urban Ghana used in the study accessed ANC more than the four recommended visits by the WHO during pregnancy. Since the study parameters considered the four or more WHO recommended visits as a measure of ANC satisfaction, hence, the study concluded that antenatal care satisfaction among urban women in Ghana was high. Study results indicate further that the source of knowledge on the need for ANC services was paramount. Information received on the need for health care use and the urgency for health care always make people seek for health due to the satisfaction that comes with it. It is therefore imperative for the broader healthcare systems to improve on the quality of services they provide in order to fully utilize ANC services. Again, antenatal care models with a minimum of eight contacts are recommended to reduce perinatal mortality and improve women's experience of care as inscribed in the 2016 WHO guidelines. 
The study also concludes that the stage of pregnancy at which women attend ANC is crucial in determining whether the recommended visits could be achieved. Early use of ANC visits was a significant factor in determining the level of satisfaction by urban women. There is prompt and timely detection of potential complications when antenatal care is sought at the early stage of pregnancy. Awareness on the need and importance of ANC use is thoroughly obtained, of which recommended visits. Hence, satisfaction to ANC use will be well pronounced if recommended ANC visits are taken in a timely manner. It is therefore, recommended that policy-makers in collaboration with other stakeholders should consider educational, regulatory, financial, and, personal and professional support interventions to recruit and retain qualified health workers in rural and remote areas.

The study again concludes that other key factors to ANC satisfaction including waiting time, attitude of caregivers and number of health staff that render care to women were significant. The study revealed that most urban women spend less than one hour during ANC visits. This acts as catalyst to ensure maximum utilization of antenatal care services among pregnant women. Thus, women as rational beings will always be interested and spend more time in ventures whose satisfaction is high. Hence, prolonged waiting time during ANC sessions act as a barrier to impede the adequate utilization of ANC visits among most urban women. It is recommended that the FANC intervention should be encouraged and supported by technical regulatory body. In addition, antenatal home visits are recommended to improve antenatal care utilization and perinatal health outcomes, particularly in far-reaching settings with low access to health services. Attitude of caregivers towards pregnant women also had positive influences on ANC satisfaction among urban women. Policy-makers should consider educational, regulatory, financial, and interventions that are both personal and professional to recruit and retain qualified health workers in rural and remote areas. ANC use demands professional care from skilled attendants, though caregivers are easily fetched in urban Ghana compared to rural places. The fewer the number of caregivers to ANC use, the greater the care and stronger the satisfaction that comes with care. It is recommended that individual ANC be preferred to group ANC for caregivers to be better informed of clients' history and individual demands and needs. For gross satisfaction to ANC use among women in urban Ghana, it is further recommended that key stakeholders such as the Ghana Ministry of Health, Ghana Health Service, the National Health Insurance Authority collaborate to build up homegrown maternal care measures that are sustainably viable, economically productive and socially recognized.

\section{Declaration}

\section{Ethics approval and consent to participate}

Ethical clearance for this study was sought for, and the Committee on Human Research and Publication Ethics (CHRPE) with reference number CHRPE/AP/407/15 of the Komfo Anokye Teaching Hospital (KATH) and Kwame Nkrumah University of Science and Technology (KNUST) gave a written approval. All participants were above 16 years.

\section{Authors' contributions}

AJA is the principal investigator of the study and participated in its conception and design. AJA and BAD carried out the literature review and drafted the entire manuscript. AJA and BAD participated in revising and finalizing the manuscript. All authors read and approved the final manuscript especially in the coding stage. Both authors were involved with the analysis and review of the manuscript.

\section{Acknowledgement}

The authors wish to thank all caregivers in selected facilities for their assistance and support before and during data gathering and management. We are again grateful 
to the Municipal Health Directorate and mostly health facility managers in the Kwabre East Municipality, Ghana, and to the women who liberally shared their time, experience and insights in this study.

\section{References}

1. Fotso JC, Ezeh AC, Essendi H. Maternal health in resource poor urban settings: how does women's autonomy influence the utilization of obstetric care services? Reprod Health. 2009; 6: 9. Ref.: http://bit.ly/303DVUF

2. Oladapo OT, Osiberu MO. Do sociodemographic characteristics of pregnant women determine their perception of antenatal care quality? Matern Child Health J. 2009; 13: 505-511. Ref.: http://bit.ly/2YmLTrn

3. Ntambue AM, Malonga FK, Dramaix-Wilmet M, Ngatu RN, Donnen P. Better than nothing? maternal, newborn, and child health services and perinatal mortality, Lubumbashi, democratic republic of the Congo: a cohort study. BMC Pregnancy Childbirth. 2016; 16: 89. Ref.: http://bit.ly/302RoMi

4. Dahiru T, Oche OM. Determinants of antenatal care, institutional delivery and postnatal care services utilization in Nigeria. Pan Afr Med J. 2015; 22: 1-17. Ref.: http://bit.ly/2xqecta

5. World Health Organization and Unicef. Antenatal care in developing countries: promises, achievements and missed opportunities: an analysis of trends, levels and differentials. 2003; 1990-2001. Ref.: http://bit.ly/2FK26Qr

6. World Health Organization. The World health report: 2005: make every mother and child count. 2005 Ref.: http://bit.ly/2RKNgxT

7. World Health Organization. Maternal mortality: to improve maternal health, barriers that limit access to quality maternal health services must be identified and addressed at all levels of the health system fact sheet (No. WHO/RHR/14.06). World Health Organization. 2014. Ref.: http://bit.ly/2J2PTZd

8. Rani M, Bonu S, Harvey S. Differentials in the quality of antenatal care in India. Int J Qual Health Care 2008; 20: 62-71. Ref.: http://bit.ly/2xmA0pJ

9. Onyeajam DJ, Xirasagar S, Khan MM, Hardin JW, Odutolu O. Antenatal care satisfaction in a developing country: a cross-sectional study from Nigeria. BMC Public Health. 2018; 18: 368. Ref.: http://bit.ly/2xkPPwX

10. Ghana Statistical Service. Ghana multiple indicator cluster survey with an enhanced malaria module and biomarker. Final Report. 2011. Ref.: http://bit.ly/2YrwCFQ

11. World Bank. World databank; world development indicators. 2018; Ref.: http://bit.ly/2JfYOQN

12. Overbosch GB, Nsowah-Nuamah NNN, Van den Boom GJM, Damnyag L. Determinants of antenatal care use in Ghana. Journal of African Economies. 2004; 13: 277-301. Ref.: http://bit.ly/2JhijgU

13. Asundep NN, Carson AP, Turpin CA, Tameru B, Agidi AT, et al. Determinants of access to antenatal care and birth outcomes in Kumasi, Ghana. J Epidemiol Glob Health. 2013; 3: 279-288. Ref.: http://bit.ly/2NpXRQi

14. Baffour-Awuah A, Mwini-Nyaledzigbor PP, Richter S. Enhancing focused antenatal care in Ghana: an exploration into perceptions of practicing midwives. Int J Africa Nurs Sci. 2015; 2: 59-64. Ref.: http://bit.ly/2FNIbQC

15. D'Ambruoso L, Abbey M, Hussein J. Please understand when I cry out in pain: women's accounts of maternity services during labour and delivery in Ghana. BMC Public Health. 2005; 5: 140. Ref.: http://bit.ly/2FIMiNE

16. Yakong VN, Rush KL, Bassett-Smith J, Bottorff JL, Robinson C. Women's experiences of seeking reproductive health care in rural Ghana: challenges for maternal health service utilization. $\mathrm{J}$ Adv Nurs. 2010; 66: 2431-2441. Ref.: http://bit.ly/2YkBug1

17. National Population Commission, Nigeria, ICF International. Nigeria demographic and health survey 2013. 2014; Ref.: http://bit.ly/2FWLg0T

18. Prytherch $\mathrm{H}$, Kagoné $\mathrm{M}$, Aninanya GA, Williams JE, Kakoko DC, et al. Motivation and incentives of rural maternal and neonatal health care providers: a comparison of qualitative findings from Burkina Faso, Ghana and Tanzania. BMC Health Services Research. 2013; 13: 149. Ref.: http://bit.ly/2Xcya5n

19. Mannava P, Durrant K, Fisher J, Chersich M, Luchters S. Attitudes and behaviours of maternal health care providers in interactions with clients: a systematic review. Global Health. 2015; 11: 36. Ref.: http://bit.ly/2LwHPBh 
20. World Health Organization. Trends in maternal mortality: 1990-2015: estimates from WHO, UNICEF, UNFPA, World Bank Group and the United Nations Population Division: executive summary (No. WHO/RHR/15.23). World Health Organization. 2015; Ref.: http://bit.ly/2YnEvw0

21. Bekele D, Bayu H, Beyene K, Bikila D. Women's Satisfaction with Care Providers Interaction and Associated Factors among Pregnant Women Attending Antenatal Clinic in Tiyo District, Arsi Zone, Ethiopia, 2016: Institutional Based Cross-Sectional Study. Research \& Reviews: J Med Sci Technol. 2017; 6: 30-38. Ref.: http://bit.ly/301u3ut

22. Akowuah JA, Agyei-Baffour $P$, Awunyo-Vitor D. Determinants of antenatal healthcare utilization by pregnant women in third trimester in peri-urban Ghana. J Trop Med. 2018; 2018: 1673517 Ref.: http://bit.ly/2ROBmmp

23. Amu H, Nyarko SH. Satisfaction with Maternal Healthcare Services in the Ketu South Municipality, Ghana: A Qualitative Case Study. BioMed Res Int. 2019; 2516469. Ref.: http://bit.ly/2RNF2VO

24. Akowuah JA, Agyei-Baffour P, Asibey BO. A Qualitative Study on the Pathways to Evidence-Based Antenatal Care in Periurban Ghana. Obstetrics and gynecology international. 2018; 2018: 4381708. Ref.: http://bit.ly/326eQdo

25. Kwabre East Health Directorate. Analyzes of Maternal Health Delivery. Kwabre East District Profile, 2013; Ref.: http://bit.ly/2J0bVeV

26. Monette DR, Sullivan TJ, DeJong CR. Applied social research: A tool for the human services. Nelson Education. 2013; Ref.: http://bit.ly/2RYkKsy

27. Burns AC, Bush RF. Marketing research. Globalization. 2006; 1: 4-8.

28. Moser CA, Kalton G. Question wording. Research Design: The Logic of Social Inquiry. 2017; 140

29. Buor D. Determinants of utilization of health services by women in rural and urban areas in Ghana. GeoJournal. 2004; 61: 89-102. Ref.: http://bit.ly/2XeKmT7

30. Aseweh Abor P, Abekah-Nkrumah G, Sakyi K, Adjasi CK, Abo, J. The socio-economic determinants of maternal health care utilization in Ghana. Int J Social Econo. 2011; 38: 628-648. Ref.: http://bit.ly/2J2tVoU

31. Arthur E. Wealth and antenatal care use: implications for maternal health care utilization in Ghana. Health economics review. 2012; 2: 14. Ref.: http://bit.ly/2J1psmC

32. Shaikh BT, Hatcher J. Complementary and alternative medicine in Pakistan: prospects and limitations. Evid Based Complement Alternat Med. 2005; 2: 139-142. Ref.: http://bit.ly/308jtC2

33. Girma F, Jira C, Girma B. Health services utilization and associated factors in Jimma zone, South west Ethiopia. Ethiop J Health Sci. 2011; 21: 91-100. Ref.: http://bit.ly/2LsNdp4

34. Dahiru T, Oche OM. Determinants of antenatal care, institutional delivery and postnatal care services utilization in Nigeria. Pan Afr Med J. 2015; 21: 321. Ref.: http://bit.ly/2xqecta

35. Ghana Health Service. The Health Sector in Ghana: Facts and Figures 2017. Accra: Government of Ghana. 2017; Ref.: http://bit.ly/2LHQEIH

36. World Health Organization. WHO recommendations on antenatal care for a positive pregnancy experience. World Health Organization. 2016; Ref.: http://bit.ly/2Nt6RE7

37. Lattof SR, Tunçalp Ö, Moran AC, Bucagu M, Chou D, et al. Developing measures for WHO recommendations on antenatal care for a positive pregnancy experience: a conceptual framework and scoping review. BMJ open. 2019; 9: e024130. Ref.: http://bit.ly/2J3ki9q

38. Owolabi OO, Wong KL, Dennis ML, Radovich E, Cavallaro FL, et al. Comparing the use and content of antenatal care in adolescent and older first-time mothers in 13 countries of west Africa: a crosssectional analysis of Demographic and Health Surveys. The Lancet Child \& Adolescent Health. 2017; 1: 203-212. Ref.: http://bit.ly/2KQPknh

39. Guagliardo MF. Spatial accessibility of primary care: concepts, methods and challenges. Int $\mathrm{J}$ Health Geogr. 2004; 3: 3. Ref.: http://bit.ly/2XvtaNW

40. Chaibva CN. Factors influencing adolescents' utilization of antenatal care services in Bulawayo, Zimbabwe. 2008; Ref.: http://bit.ly/2Xt33Cv

41. Ministry of Health, Republic of Ghana. Health Sector Medium Term Development Plan 2014-2017. Accra: Government of Ghana, 2014; Ref.: http://bit.ly/2L3wvxj

42. Vail J. Antenatal utilization, family planning and fertility preferences in Tari. Papua and New Guinea medical journal. 2002; 45: 134-141. Ref.: http://bit.ly/2S2GXpA 
43. Agboolah AR. Utilization of antenatal care services in Atwima Nwabiagya District (Doctoral dissertation). 2009. Ref.: http://bit.ly/2KSixOB

44. Cimiotti JP, Aiken LH, Sloane DM, Wu ES. Nurse staffing, burnout, and health care-associated infection. Am J Infect Control. 2012; 40: 486-490. Ref.: http://bit.ly/2Nt7jIN

45. Okonofua F, Ogu R, Agholor K, Okike O, Abdus-Salam R, et al. Qualitative assessment of women's satisfaction with maternal health care in referral hospitals in Nigeria. Reproductive health. 2017; 14 : 44. Ref.: http://bit.ly/2KOQaAQ

46. Greenaway ES, Leon J, Baker DP. Understanding the association between maternal education and use of health services in Ghana: exploring the role of health knowledge. J Biosoc Sci. 2012; 44: 733-747. Ref.: http://bit.ly/2XM7ZGV

47. Nuraini E, Parker E. Improving knowledge of antenatal care (ANC) among pregnant women: a field trial in central Java, Indonesia. Asia Pac J Public Health. 2005; 17: 3-8. Ref.: http://bit.ly/2XFI186

48. Tura G. Antenatal care service utilization and associated factors in Metekel Zone, Northwest Ethiopia. Ethiopian Journal of Health Sciences. 2009; 19. Ref.: http://bit.ly/2LwHPSa

49. Kambala C, Lohmann J, Mazalale J, Brenner S, De Allegri M, et al. How do Malawian women rate the quality of maternal and newborn care? Experiences and perceptions of women in the central and southern regions. BMC Pregnancy and Childbirth. 2015; 15: 1-19. Ref.: http://bit.ly/2NnnhOi

50. Ghana Statistical Service (2004). Ghana. Statistical Service, Noguchi Memorial Institute for Medical Research and ORC Macro. MEASURE/DHS+ (Programme), 2004. Ghana demographic and health survey, 2003.

51. Matua AG. Determinants of maternal choice for place of delivery in Ayivu county, Arua district, Uganda. Africa Journal of Nursing and Midwifery. 2004; 6: 33-38. Ref.: http://bit.ly/2LvkXIS

52. Ziyani IS, King LJ, Ehlers VJ. Using triangulation of research methods to investigate family planning practice in Swaziland. Africa Journal of Nursing and Midwifery. 2004; 6: 12-17. Ref.: http://bit.ly/2LtMmEN 